\title{
STUDI EKSPERIMEN KOMPOSISI GAS BUANG AKIBAT PERUBAHAN MAIN JET NOZZLE PADA SISTEM KARBURATOR MESIN DENGAN MENGGUNAKAN BAHAN BAKAR PREMIUM DAN PERTAMAX
}

\author{
Riki Candra Putra ${ }^{1}$, Septian Wahyu Kurniawan ${ }^{2}$ \\ ${ }^{1,2}$ Program Studi Teknik Mesin, Fakultas Teknik, Universitas Muhammadiyah Tangerang \\ Jl. Perintis Kemerdekaan I/33 Cikokol-Tangerang 15118 \\ E-mail: ${ }^{1}$ rikiumt@gmail.com
}

\begin{abstract}
The purpose of this study was to determine the difference in the rate of motorcycle specific fuel consumption after replacing the main jet $R 105 \mathrm{cc}$ to the $110 \mathrm{cc}$ Suzuki smash using premium and Pertamax fuel and to determine the comparison of motorcycle specific exhaust emissions using premium and Pertamax fuels. Examination of exhaust emissions and the rate of fuel consumption carried out on a yamaha vega $R$ engine in 2004 using the Stargas 898 brand Exhaust Gas Analyzer and burette measuring devices are used for testing fuel consumption. Data was collected at $2000 \mathrm{rpm}, 4000 \mathrm{rpm}$ and $5000 \mathrm{rpm}$ rotation. The test results showed differences in levels of exhaust emissions and the rate of fuel consumption produced by the two main jets, namely the main jet yamaha vega $R$ (90.0) and the main jet suzuki smash (92.5). For the level of exhaust emissions produced by both the main jet suzuki smash (92.5) and Yamaha Vega R (90.0) with premium fuel has a higher value (less good) when compared with the levels of Pertamax exhaust emissions. The fuel consumption rate for the two main jets that use premium is far more wasteful compared to those using Pertamax.

Keywords: main jet, emissions, consumption rates, fuel.
\end{abstract}

\begin{abstract}
Abstrak
Tujuan Penelitian untuk mengetahui perbedaan laju konsumsi bahan bakar spesifik sepeda motor setelah penggantian main jet vega $\mathrm{R} 105 \mathrm{cc}$ ke suzuki smash $110 \mathrm{cc}$ dengan menggunakan bahan bakar premium dan pertamax dan untuk mengetahui perbandingan emisi gas buang spesifik sepeda motor dengan menggunakan bahan bakar premium dan pertamax. Pengujian emisi gas buang dan laju konsumsi bahan bakar yang dilakukan pada mesin yamaha vega R tahun 2004 menggunakan Exhaust Gas Analyzer merk Stargas 898. dan alat ukur buret digunakan untuk pengujian konsumsi bahan bakar. Pengambilan data dilakukan pada putaran $2000 \mathrm{rpm}$, $4000 \mathrm{rpm}$ dan $5000 \mathrm{rpm}$. Hasil pengujian menunjukkan adanya perbedaan kadar emisi gas buang dan laju konsumsi bahan bakar yang dihasilkan oleh kedua main jet yaitu main jet yamaha vega $\mathrm{R}(90,0)$ dan main jet suzuki smash (92,5). Untuk kadar emisi gas buang yang dihasilkan kedua main jet suzuki smash $(92,5)$ dan yamaha vega $\mathrm{R}(90,0)$ dengan bahan bakar premium memiliki nilai yang lebih tinggi (kurang baik) jika dibandingkan dengan kadar emisi gas buang pertamax. Laju konsumsi bahan bakar untuk kedua main jet yang menggunakan premium jauh lebih boros dibandingkan dengan yang menggunakan pertamax.
\end{abstract}

Kata kunci: main jet, emisi, laju konsumsi, bahan bakar.

\section{Pendahuluan}

Pada saat ini motor bakar merupakan mesin yang sering dijumpai dan digunakan pada berbagai keperluan untuk membantu kebutuhan manusia seperti keperluan transportasi, pemakaian rumah tangga dan industri.

Motor bakar adalah salah satu jenis dari mesin konversi energi yang mengubah energi termal untuk melakukan kerja mekanik atau mengubah tenaga kimia bahan bakar menjadi tenaga mekanis (Suyanto \& Wardan. 1989). Energi pada motor bakar diperoleh dari proses pembakaran bahan bakar dikonversikan menjadi energi mekanik, yang kemudian energi mekanik ini yang akan dimanfaatkan untuk proses tertentu (Fardiaz \& Srikandi, 1992). 
Pada dasarnya energi dari motor bakar tidak bisa langsung dimanfaatkan jika tidak dihubungkan pada mesin atau alat tertentu (Kabib \& Masruki, 2009). Dalam pemilihan suatu motor bakar haruslah disesuaikan dengan kebutuhan alat yang akan dihubungkan pada motor bakar tersebut. Jika yang dibutuhkan tenaga misalnya untuk mengangkat beban, tentulah torsi dari motor bakar yang dibutuhkan. Jika yang dibutuhkan kecepatan, maka daya dari motor bakar yang dibutuhkan.

Oleh sebab itu, sebagai parameter pemilihan yaitu dengan cara mengetahui performa dari mesin motor bakar yang akan dipilih (Kristanto et. All, 2001). Parameter tesebut dapat berupa torsi, daya, dan konsumsi bahan bakar dari motor bakar tersebut. Jika tidak memperhatikan aspek tersebut, maka pada pengoperasian motor bakar tidak akan efisien bahkan akan mengakibatkan kerusakan baik dari motor bakar tersebut ataupun mesin yang akan dihubungkan (Sayoga et. All, 2012.

Salah satu faktor yang mempengaruhi kinerja motor bakar yaitu nosel atau main jet. Fungsi nosel adalah pengkabutan bahan bakar atau ada yang menyebut dengan Injektor (Ellyanie. 2011).

Disebut injector karena tugas dari komponen ini adalah menginjeksi, dan disebut pengabut karena pengaruh variasi main jet nosel pada sistem karburator keluar dari komponen ini dalam bentuk kabut, sedangkan disebut nosel karena ujung komponen ini memiliki luas penampang yang semakin mengecil. Dari hal tersebut bisa dilihat pada kondisi nosel yang berbeda akan mengakibatkan perbedaan berapa persen motor bakar dapat mengeluarkan daya dan torsi maksimal serta dapat dilihat juga berapa nilai konsumsi bahan bakar pada setiap variasi nosel pada pengujian.

Tujuan dari penelitian ini adalah untuk mengetahui perbedaan laju konsumsi bahan bakar spesifik sepeda motor setelah penggantian main jet Vega R $105 \mathrm{cc}$ menjadi main jet Suzuki Smash 110 cc dengan menggunakan bahan bakar premium dan pertamax dan untuk mengetahui perbandingan emisi gas buang spesifik sepeda motor dengan menggunakan bahan bakar Premium dan pertamax.

\section{Metode Penelitian}

Metode penelitian dalam penelitian ini adalah menggunakan metode eksperimen. Desain eksperimen yang digunakan dalam penelitian ini adalah treatment by subject yaitu beberapa variasi perlakuan secara berturut-turut kepada kelompok subjek yang sama (Nawawi et. All, 1996).

Variabel penelitian yang digunakan dalam penelitian ini antara lain pengukuran kadar emisi gas buang dengan menggunakan variasi main jet Yamaha Vega R 105 CC dan main jet Suzuki smash 110 CC dengan menggunakan bahan bakar premium dan pertamax dan pengukuran konsumsi bahan bakar (banyaknya bahan bakar yang dikonsumsi dalam satuan cc/menit).

Eksperiman dilakukan di bengkel Ultra Speed Racing J1. Daan Mogot Kota Tangerang, dengan menggunakan sdepeda motor dengan merk Yamaha Vega R 105 cc tahun 2004 dan dua jenis main jet yaitu main jet Yamaha Vega R 105 CC $(90,0)$ dan main jet Suzuki Smash 110 CC $(92,5)$.

Alat yang digunakan saat penelitian yaitu Exhaust Gas Analyzer Merk Stargas 898, stopwatch, burner ukur, dan tool set dan burret ukur. Pada saluran gas buang pada kendaraan dimasuki sensor dari alat exhaust gas analyzer merk Stargas 898. Data informasi kadar emisi gas buang pada setiap putaran mesin akan ditampilkan pada sebuah layar monitor selembar kertas print.

Tahapan-tahapan pengambilan data adalah sebagai berikut:

- Memposisikan sepeda motor pada posisi standar 2.

- Memasang selang burret ukur pada lubang masuk bahan bakar pada karburator. Kemudian mengisi buret test dengan premium. 
- Memanaskan motor hingga mendekati suhu kerja mesin selama (2-3 menit) yaitu $\pm 80^{\circ} \mathrm{C}$.

- Setelah proses pemanasan di atas selesai, baru memulai proses pengambilan data pertama dengan menggunakan bahan bakar premium.

- Mengatur putaran mesin dengan membuka gas hingga pada tachometer digital menunjukkan angka $2000 \mathrm{rpm}$. Setelah mencapai 4000 rpm kemudian melakukan pengambilan data pengukuran emisi dan konsumsi bahan bakar.

- Mencatat laju konsumsi bahan bakar bersamaan dengan pengujian emisi gas buang, konsumsi bahan bakar diukur dengan banyaknya bahan bakar bahan bakar yang digunakan oleh sepeda motor dalam waktu 1 menit dengan menggunakan alat burret ukur dan stopwatch.

- Setelah mencatat data yang diperoleh, kemudian melakukan pengamatan juga pada putaran mesin $4000 \mathrm{rpm}$ dan 5000 rpm. Dan lakukan pengambilan data serupa dengan sewaktu putaran mesin $2000 \mathrm{rpm}$.

- Pengujian kembali dilakukan dengan mengulang langkah-langkah pengujian awal dengan menggunakan main jet Suzuki smash $110 \mathrm{cc}$.

Pengambilan data yang dilakukan adalah dengan mencatat jumlah konsumsi bahan bakar dan kandungan emisi yang dihasilkan yang dilakukan selama pengujian. Adapun data penelitian yang diamati dan dicatat adalah konsumsi bahan bakar dan kandungan emisi dengan menggunakan variasi main jet yaitu main jet Vega $\mathrm{R}$ 90,0 dan main Jet Smash yaitu 92,5 dan 2 jenis bahan bakar yaitu premium dan pertamax yang dihasilkan yang dilakukan selama pengujian

\section{Hasil dan Pembahasan}

Data hasil penelitian yang diperoleh antara lain berupa kadar emisi gas buang
$\mathrm{CO}, \mathrm{CO}_{2}, \mathrm{HC}, \mathrm{O}_{2}$ dan konsumsi bahan bakar dengan perlakuan merubah main jet 90,0 (standar Yamaha Vega R) dengan main jet 92,5 (standar Suzuki smash $110 \mathrm{cc})$.

Pengambilan data dilakukan dalam tiga varian putaran mesin yaitu putaran rendah (2000 rpm), sedang (4000 rpm) dan tinggi (5000 rpm), sehingga akan diketahui seberapa besar perbedaan hasil Kadar Emisi gas yang lebih signifikan dari tiaptiap main jet, serta berapa banyak bahan bakar yang digunakan untuk tiap-tiap main Jet.

Beberapa variasi hasil emisi gas buang pada pengujian terhadap varian main jet standard vega $\mathrm{R}(90,0)$ dan standard smash (92,5) menggunakan bahan bakar pertamax dan premium pada putaran 2000 , 4000, 5000 Rpm dapat dilihat pada tabeltabel sebagai berikut:

A. Pengujian emisi gas buang dengan menggunakan bahan bakar premium dan main jet Suzuki Smash $(92,5)$ dapat dilihat pada tabel 1 .

Tabel 1. Emisi gas buang menggunakan main jet 92,5 standard Suzuki Smash bahan bakar premium

\begin{tabular}{ccccc}
\hline & \multicolumn{4}{c}{ Kadar emisi menggunakan } \\
premium \\
\cline { 2 - 5 } RPM & $\mathrm{CO}$ & $\mathrm{CO}_{2}$ & $\mathrm{HC}$ & $\mathrm{O}_{2}$ \\
& $(\%)$ & $(\%)$ & $(\mathrm{ppm})$ & $(\%)$ \\
\hline 2000 & 6,270 & 2,47 & 3189 & 11,90 \\
\hline 4000 & 6,037 & 2,85 & 802 & 12,00 \\
\hline 5000 & 4,971 & 4,23 & 380 & 10,65 \\
\hline
\end{tabular}

B. Pengujian emisi gas buang dengan menggunakan bahan bakar Premium dan main jet Yamaha Vega $\mathrm{R}(90,0)$ dapat dilihat pada tabel 2 .

Tabel 2. Emisi gas buang menggunakan main jet 90,0 standard Vega $\mathrm{R}$ bahan bakar premium

\begin{tabular}{ccccc}
\hline & \multicolumn{4}{c}{ Kadar emisi menggunakan } \\
premium \\
\cline { 2 - 5 } RPM & $\mathrm{CO}$ & $\mathrm{CO}_{2}$ & $\mathrm{HC}$ & $\mathrm{O}_{2}$ \\
& $(\%)$ & $(\%)$ & $(\mathrm{ppm})$ & $(\%)$ \\
\hline 2000 & 6,246 & 2,56 & 2813 & 11,24 \\
\hline
\end{tabular}




\begin{tabular}{ccccc}
\hline 4000 & 5,502 & 3,02 & 528 & 11,69 \\
\hline 5000 & 4,880 & 4,38 & 347 & 9,71 \\
\hline
\end{tabular}

C. Pengujian emisi gas buang dengan menggunakan bahan bakar pertamax dan main jet Yamaha Vega $\mathrm{R}(90,0)$ dapat dilihat pada tabel 3 .

Tabel 3. Emisi gas buang menggunakan main jet 90,0 standard Vega $\mathrm{R}$ bahan bakar pertamax

\begin{tabular}{ccccc}
\hline & \multicolumn{4}{c}{ Kadar emisi menggunakan } \\
pPM & \multicolumn{4}{c}{ pertamax } \\
\cline { 2 - 5 } & $\mathrm{CO}$ & $\mathrm{CO}_{2}$ & $\mathrm{HC}$ & $\mathrm{O}_{2}$ \\
& $(\%)$ & $(\%)$ & $(\mathrm{ppm})$ & $(\%)$ \\
\hline 2000 & 5,817 & 2,86 & 2349 & 10,78 \\
\hline 4000 & 4,370 & 3,44 & 194 & 10,95 \\
\hline 5000 & 3,943 & 4,98 & 231 & 9,14 \\
\hline
\end{tabular}

D. Pengujian Emisi gas buang dengan menggunakan bahan bakar Pertamax dan main jet Suzuki Smash $(92,5)$ dapat dilihat pada tabel 4 .

Tabel 4. Emisi gas buang Menggunakan main jet 92,5 standard Suzuki Smash bahan bakar pertamax.

\begin{tabular}{ccccc}
\hline & \multicolumn{4}{c}{ Kadar emisi menggunakan } \\
RPM & $\mathrm{CO}$ & $\mathrm{CO}_{2}$ & $\mathrm{HC}$ & $\mathrm{O}_{2}$ \\
& $(\%)$ & $(\%)$ & $(\mathrm{ppm})$ & $(\%)$ \\
\hline 2000 & 6,164 & 2,68 & 2726 & 10,85 \\
\hline 4000 & 5,128 & 3,06 & 397 & 11,49 \\
\hline 5000 & 4,535 & 4,44 & 307 & 9,37 \\
\hline
\end{tabular}

Pada keadaan idle, gas $\mathrm{CO}$ yang terbentuk sangat besar, tetapi dari tiap variasi bahan bakar dan main jet yang ada menunjukan adanya perubahan kadar emisi gas CO.

Pada pemeriksaan kadar emisi Karbon monoksida (CO) nilai paling tinggi didapat pada putaran paling rendah yaitu pada 2000 rpm untuk semua variasi main jet dan bahan bakar. Kadar tertinggi terjadi pada pengujian main jet Suzuki Smash $(92,5)$ dengan bahan bakar premium dan kadar terendah terjadi pada pengujian main jet Yamaha Vega R $(90,0)$ dan bahan bakar pertamax.
Pada pemeriksaan kadar emisi karbon dioksida $\left(\mathrm{CO}_{2}\right)$ nilai paling tinggi didapat pada putaran paling tinggi yaitu pada $5000 \mathrm{rpm}$ untuk semua variasi main jet dan bahan bakar. Nilai kadar CO paling tinggi terjadi pada pengujian main jet Yamaha Vega R $(90,0)$ dan bahan bakar pertamax sedangkan nilai kadar $\mathrm{CO}$ paling rendah terjadi pada pengujian main jet Suzuki Smash $(92,5)$ dan bahan bakar premium.

Pada pemeriksaan kadar emisi hidrokarbon (HC) nilai paling tinggi didapat pada putaran paling rendah yaitu 2000 rpm sedangkan nilai paling rendah terjadi pada putaran paling tinggi yaitu 5000 rpm, meskipun terjadi perbedaan tingkatan nilai kadar $\mathrm{HC}$ pada pengujian main jet Yamaha Vega $\mathrm{R}(90,0)$ bahan bakar pertamax nilai terendah terjadi pada putaran menengah yaitu $4000 \mathrm{rpm}$, namun rata-rata kenaikan nilai $\mathrm{HC}$ untuk semua pengujian terjadi mulai dari kecepatan tinggi ke rendah.

Pada pemeriksaan kadar emisi oksigen $\left(\mathrm{O}_{2}\right)$ nilai paling tingi terjadi pada kecepatan menengah yaitu $4000 \mathrm{rpm}$ sedangkan nilai terendah terjadi pada kecepatan tertinggi yaitu 5000 rpm untuk semua variasi main jet dan bahan bakar. Kadar tertinggi terjadi pada pengujian main jet Suzuki Smash $(92,5)$ dan bahan bakar premium sedangkan kadar terendah terjadi pada pengujian main jet Yamaha Vega $\mathrm{R}$ $(90,0)$ dan bahan bakar pertamax.

Pada variasi Pembentukan gas CO sangat dipengaruhi oleh perbandingan udara bahan bakar, bahan bakar pertamax 92 dapat membantu proses pembakaran didalam ruang bakar, dikarenakan pertamax 92 mempunyai nilai oktan yang tinggi dibanding dengan Premium. Campuran yang kurus relatif lebih sedikit menghasilkan gas $\mathrm{CO}$, karena suplai oksigen yang dibutuhkan untuk pembakaran sempurna menjadi lebih banyak, sehingga konsentrasi gas $\mathrm{CO}$ yang timbul karena pembakaran yang kurang sempurna menjadi turun. 
Jika dilihat dari kadar $\mathrm{CO}, \mathrm{CO}_{2}$, dan $\mathrm{HC}$, pada setiap variasi dan putaran proses pembakarannya menjadi semakin sempurna ada pengujian main jet 90,0 dan bahan bakar pertamax pada putaran $5000 \mathrm{rpm}$ karena kadar oksigen semakin kecil (Putra et. All, 2015). Dari data yang didapat pada pengujian main jet 90,0 dan bahan bakar pertamax juga menunjukan adanya penurunan kadar emisi $\mathrm{CO}$ dan $\mathrm{HC}$ yang dihasilkan. Perbedaan kecepatan bakar dan ketahanan bahan bakar tersebut pada kondisi terbakar sendiri sebelum waktunya terbakar oleh pengapian menjadi faktor yang penting dalam mempengaruhi kadar emisi. Pada prinsipnya $\mathrm{CO}_{2}$ berbanding terbalik dengan gas buang karbon monoksida (CO), apabila $\mathrm{CO}_{2}$ tinggi maka $\mathrm{CO}$ akan rendah, karena dalam proses pembakaran yang hampir sempurna $\mathrm{CO}_{2}$ harus tinggi dan $\mathrm{O}_{2}$ rendah (Ellyane, 2011:439).

Kemudian pembahasan berikut adalah data-data konsumsi bahan bakar menggunakan variasi main jet standard Vega R $(90,0)$ dan standard Smash $(92,5)$ dengan menggunakan bahan bakar pertamax dan premium pada putaran 2000, 4000, 5000 Rpm dapat dilihat pada tabeltabel sebagai berikut:

A. Pengujian konsumsi bahan bakar yang menggunakan main jet 90,0 standard Yamaha Vega $\mathrm{R}$ dan bahan bakar premium dapat dilihat pada tabel 5 .

Tabel 5. Konsumsi bahan bakar menggunakan main jet 90,0 standard Yamaha Vega R dan bahan bakar premium.

\begin{tabular}{cccccc}
\hline & \multicolumn{5}{c}{ Waktu Yang Diperlukan } \\
\cline { 2 - 6 } RPM & $\begin{array}{c}\text { Uji 1 } \\
\text { (min) }\end{array}$ & $\begin{array}{c}\text { Uji 2 } \\
\text { (min) }\end{array}$ & $\begin{array}{c}\text { Uji 3 } \\
\text { (min) }\end{array}$ & $\begin{array}{c}\text { Rata- } \\
\text { rata } \\
\text { (min) }\end{array}$ & $\begin{array}{c}\text { cc / } \\
\text { min }\end{array}$ \\
\hline 2000 & 0,54 & 0,54 & 0,54 & 0,54 & 9,25 \\
\hline 4000 & 0,28 & 0,28 & 0,27 & 0,28 & 17,85 \\
\hline 5000 & 0,25 & 0,25 & 0,25 & 0,25 & 20 \\
\hline
\end{tabular}

B. Pengujian konsumsi bahan bakar yang menggunakan main jet 92,5 standard Suzuki Smash dan bahan bakar premium dapat dilihat pada tabel 6 .

Tabel 6. Konsumsi bahan bakar menggunakan main jet 92,5 standard Suzuki Smash 110cc bahan bakar premium.

Waktu Yang Diperlukan Menghabiskan 5 cc Premium

\begin{tabular}{cccccc} 
RPM & $\begin{array}{c}\text { Uji 1 } \\
\text { (min) }\end{array}$ & $\begin{array}{c}\text { Uji 2 } \\
\text { (min) }\end{array}$ & $\begin{array}{c}\text { Uji 3 } \\
\text { (min) }\end{array}$ & $\begin{array}{c}\text { Rata- } \\
\text { rata } \\
\text { (min) }\end{array}$ & $\begin{array}{c}\text { cc / } \\
\text { min }\end{array}$ \\
\hline 2000 & 0,43 & 0,43 & 0,43 & 0,43 & 11,63 \\
\hline 4000 & 0,25 & 0,27 & 0,26 & 0,26 & 19,23 \\
\hline 5000 & 0,21 & 0,21 & 0,21 & 0,21 & 23,80 \\
\hline
\end{tabular}

C. Pengujian konsumsi bahan bakar yang menggunakan main jet 90,0 standard Yamaha Vega $\mathrm{R}$ dan bahan bakar pertamax dapat dilihat pada tabel 7 .

Tabel 7. Konsumsi bahan bakar menggunakan main jet 90,0 standard Yamaha Vega R bahan bakar pertamax.

Waktu Yang Diperlukan

Menghabiskan 5 cc Pertamax

\begin{tabular}{cccccc}
\cline { 2 - 6 } RPM & $\begin{array}{c}\text { Uji 1 } \\
(\text { min })\end{array}$ & $\begin{array}{c}\text { Uji 2 } \\
(\text { min) }\end{array}$ & $\begin{array}{c}\text { Uji 3 } \\
(\text { min })\end{array}$ & $\begin{array}{c}\text { Rata- } \\
\text { rata } \\
\text { (min) }\end{array}$ & $\begin{array}{c}\text { cc / } \\
\text { min }\end{array}$ \\
\hline 2000 & 0,56 & 0,55 & 0,56 & 0,55 & 8,92 \\
\hline 4000 & 0,32 & 0,33 & 0,34 & 0,33 & 15,15 \\
\hline 5000 & 0,28 & 0,27 & 0,28 & 0,27 & 17,85 \\
\hline
\end{tabular}

D. Pengujian konsumsi bahan bakar yang menggunakan main jet 92,5 standard Suzuki Smash dan bahan bakar Pertamax dapat dilihat pada tabel 8 .

Tabel 8. Konsumsi bahan bakar motor yang menggunakan main jet 92,5 standard Suzuki Smash bahan bakar pertamax.

\begin{tabular}{cccccc}
\hline & \multicolumn{5}{c}{ Waktu Yang Diperlukan } \\
\cline { 2 - 6 } RPM & $\begin{array}{c}\text { Uji 1 } \\
(\mathrm{min})\end{array}$ & $\begin{array}{c}\text { Uji 2 } \\
(\mathrm{min})\end{array}$ & $\begin{array}{c}\text { Uji 3 } \\
(\mathrm{min})\end{array}$ & $\begin{array}{c}\text { Rata- } \\
\text { rata } \\
(\mathrm{min})\end{array}$ & $\begin{array}{c}\mathrm{cc} / \\
\mathrm{min}\end{array}$ \\
\hline 2000 & 0,55 & 0,55 & 0,54 & 0,54 & 9,25 \\
\hline 4000 & 0,29 & 0,28 & 0,29 & 0,29 & 17,24 \\
\hline
\end{tabular}




\begin{tabular}{llllll}
\hline 5000 & 0,26 & 0,26 & 0,27 & 0,26 & 19,23 \\
\hline
\end{tabular}

Berdasarkan data-data pada tabel di atas dapat disederhanakan menjadi bentuk grafik pada gambar 1 agar lebih mudah dibahas.

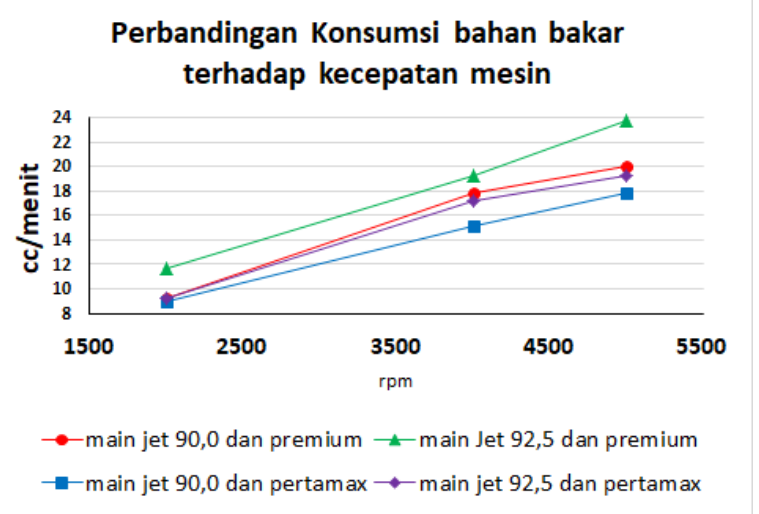

Gambar 1. Perbandingan konsumsi bahan bakar dan kecepatan mesin

Pada putaran $2000 \quad$ Rpm menggunakan main jet Vega $\mathrm{R}$ yaitu 90,0. laju konsumsi bahan bakar untuk menghabiskan $5 \mathrm{cc}$ premium 88 pada pengujian pertama adalah 0,54 menit, pada pengujian kedua menghasilkan angka yang sama yauitu 0,54 menit, begitu pula pada pengujian ketiga yaitu 0,54 menit. Kemudian diambil rata - rata adalah 0,54 menit. Dan dapat dihasilkan data pada putaran 2000 rpm laju konsumsi bahan bakar adalah 9,25 cc/menit.

Dilanjutkan laju konsumsi bahan bakar untuk menghabiskan 5cc pertamax 92 masih menggunakan main jet Vega $\mathrm{R}$ yaitu 90,0. pada pengujian pertama adalah 0,56 menit, pada pengujian kedua menghasilkan angka yang sama yaitu 0,55 menit, begitu pula pada pengujian ketiga yaitu 0,56 menit. Kemudian diambil rata rata adalah 0,55 menit. Dan dapat dihasilkan data pada putaran $2000 \mathrm{rpm}$ laju konsumsi bahan bakar adalah 8,92 cc/menit.

Kemudian laju Konsumsi Bahan bakar menggunakan main jet Suzuki Smash 92,5 Dan bahan bakar premium 88. Laju konsumsi bahan bakar untuk menghabiskan 5cc Premium 88 pada pengujian pertama adalah 0,43 menit, pada pengujian kedua menghasilkan angka yang sama yaitu 0,43 menit, begitu pula pada pengujian ketiga yaitu 0,43 menit. Kemudian diambil rata rata adalah 0,43 menit. Dan dapat dihasilkan data pada putaran $2000 \mathrm{rpm}$ laju konsumsi bahan bakar adalah 11,63 cc/menit.

Dilanjutkan laju konsumsi bahan bakar menggunakan main jet Suzuki Smash 92,5 dan bahan bakar pertamax 92. Laju konsumsi bahan bakar untuk menghabiskan 5cc pertamax 92 pada pengujian pertama adalah 0,55 menit, pada pengujian kedua menghasilkan angka yang sama yaitu 0,55 menit, begitu pula pada pengujian ketiga yaitu 0,54 menit. Kemudian diambil rata rata adalah 0,54 menit. Dan dapat dihasilkan data pada putaran $2000 \mathrm{rpm}$ laju konsumsi bahan bakar adalah 9,25 cc/menit.

Semakin berkurang kandungan oktan dalam bensin maka konsumsi bahan bakar akan semakin meningkat. Sebaliknya dengan angka oktan yang lebih tinggi memiliki tingkat pembakaran yang lebih sempurna, panas yang dihasilkan dari pembakaran lebih tinggi, energi panas menjadi gerak juga lebih tinggi. Hal tersebut yang menjadikan konsumsi bahan bakar menjadi lebih efisien.

Pemakaian bahan bakar premium membuat konsumsi bahan bakar menjadi lebih meningkat. Salah satu sifat yang dimiliki pada pertamax yaitu memiliki kemampuan untuk menguap lebih baik hal tersebut mengindikasikan pemeratan penguapan pada saat akselerasi (Soenarta et. All, 1995).

\section{Kesimpulan}

Berdasarkan analisis dan data-data yang diperoleh dari hasil pengujian tentang analisi pengaruh perubahan main jet terhadap laju konsumsi bahan bakar dan emisi gas buang dengan menggunakan bahan bakar pertamax dan premium dapat diambil kesimpulan sebagai berikut : 
- Bahan bakar pertamax dapat mengurangi laju konsumsi bahan bakar dibandingkan dengan bahan bakar jenis premium pada sepeda motor. Dikarenakan semakin tinggi oktan bahan bakar maka semakin rendah laju konsumsi bahan bakarnya, begitu pula sebaliknya semakin rendah oktan suatu bahan bakar maka semakin besar pula laju konsumsi bahan bakarnya. Laju konsumsi bahan bakar tertinggi terjadi pada main jet vega $r(90,0)$ dan bahan bakar pertamax yaitu sebesar 8,92 cc/menit pada putaran mesin $2000 \mathrm{rpm}$. Laju konsumsi bahan bakar paling terendah terjadi pada putaran 5000 Rpm, pada bahan bakar premium dengan main jet Suzuki Smash 92,5 yaitu sebesar 23,80 cc/menit.

- Kadar emisi gas buang juga cenderung meningkat pada rpm rendah dan menurun pada rpm tinggi dikarenakan semakin tinggi rpm maka pembakaran smpurna dan timing semakin tepat. Kadar emisi juga dipengaruhi oleh kadar oktan pada bahan bakar. Kadar emisi terendah terjadi pada putaran 5000 Rpm dengan menggunakan bahan bakar pertamax dan main jet Vega $\mathrm{R}$ 90,0 yaitu kadar CO 3,943\%, kadar CO2 4,98 dan kadar HC 231 ppm. Dan kadar emisi tertinggi pada main jet smash 92,5 menggunakan bahan bakar premium yaitu kadar $\mathrm{CO} 4,971 \%$, kadar $\mathrm{CO} 24,23 \%$, kadar HC 380 ppm.

\section{Daftar pustaka}

Ellyanie. 2011. Pengaruh Penggunaan ThreeWay Catalytic Converter Terhadap Emisi Gas Buang Pada Kendaraan Toyota Kijang Innova. Prosiding Seminar Nasional Avoer, Hal 437-445 ISBN : 979-587-3954

Fardiaz, Srikandi. 1992. Polusi Air \& Udara. Yogyakarta: Kanisius.

Kabib, Masruki. 2009. Pengaruh pemakaian campuran premium dengan champor terhadap performasi dan emisi gas buang mesin Toyota kijang seri 4K. Jurnal Sain dan Teknologi. Vol. 2 No. 2. Hal : 1-17

Keputusan Direktur Jenderal Minyak dan Gas Bumi. Nomor : 3674K/24/DJM/2006, Tanggal 17 Maret 2006

Kristanto, Philip, Willyanto, dan Michael. 2001. Peningkatan Unjuk Kerja Motor Bensin Empat Langkah Dengan Penggunan Methyl Tertiary Buthyl Ether Pada Bensin. Jurnal Teknik Mesin. Vol. 3, No. 2. Hal 57-62.

Nawawi, Hadari, dan Mimi Martini. 1996. Penelitian terapan. Yogyakarta : Gajah Mada universy Press.

Permen Lingkungan Hidup Nomor 05. 2006.

Ambang Batas Emisi Gas Buang Kendaraan Bermotor Lama.

Putra, Riza, Azis. 2015. Analisis komposisi Gas Buang Akibat Perubahan Main Jet Nozzle Pada Sistem Karburator Mesin. Jurnal Poros, Vol. 13, no.2, hal. 62-74.

Raharjo, Winarno Dwi dan Karnowo. 2008. Mesin Konversi Energi. Semarang:

Universitas Negeri Semarang Press

Supraptono. 2004. Bahan Bakar dan Pelumas.

Semarang: Universitas Negeri Semarang Press.

Suyanto, Wardan. 1989. Teori Motor Bensin. Jakarta : Departemen Pendidikan Dan Kebudayaan Direktorat Jenderal Pendidikan Tinggi Proyek Pengembangan Lembaga Pendidikan Tenaga Kependidikan.

Sayoga, I Made Adi. 2012. Pengaruh Methanol Terhadap Torsi, Daya Epektif Konsumsi Bahan Bakar Spesifik Pada Mesin Daihatsu Feroza 1994. Dinamika Teknik Mesin. Vol. 2, No. 1, Hal. 1-6

Soenarta, Nakoela, dan Shochi Furuhama. 1995. Motor Serba Guna. Jakarta : PT. Pradnya Paramita. 